\title{
« Lumières radicales, radicalisme des Lumières ", coordonné par Jean Mondot et Cécile Révauger
}

\section{Marc Belissa}

\section{(2) OpenEdition Journals}

Édition électronique

URL : https://journals.openedition.org/ahrf/11740

DOI : $10.4000 /$ ahrf. 11740

ISSN : 1952-403X

Éditeur :

Armand Colin, Société des études robespierristes

Édition imprimée

Date de publication : 1 septembre 2010

Pagination : 204-205

ISBN : 978-2-200-92633-5

ISSN : 0003-4436

Référence électronique

Marc Belissa, « «Lumières radicales, radicalisme des Lumières », coordonné par Jean Mondot et Cécile Révauger », Annales historiques de la Révolution française [En ligne], 361 | juillet-septembre 2010, mis en ligne le 22 mars 2011, consulté le 24 avril 2022. URL : http://journals.openedition.org/ahrf/ 11740 ; DOI : https://doi.org/10.4000/ahrf.11740

Ce document a été généré automatiquement le 24 avril 2022.

Tous droits réservés 


\title{
«Lumières radicales, radicalisme des Lumières ", coordonné par Jean Mondot et Cécile Révauger
}

\author{
Marc Belissa
}

\section{RÉFÉRENCE}

"Lumières radicales, radicalisme des Lumières ", Lumières, no 13, coordonné par Jean Mondot et Cécile Révauger, 1er semestre 2009, Bordeaux, Presses Universitaires de Bordeaux, 205 p., ISBN 978-2-86781-608-6, $22 €$.

1 Ce numéro de la revue Lumières est consacré au concept de "Lumières radicales ", devenu paradigme et objet d'un débat parmi les philosophes et les historiens spécialistes des Lumières, depuis les ouvrages de Margaret Jacob, The Radical Enlightenment, Pantheists, Freemasons and Republicans (1981) et surtout de Jonathan Israel, Radical Enlightenment, Philosophy and the Making of Modernity, 1650-1750 (2001, traduit en français en 2005) et Enlightenment Contested, Philosophy, Modernity and the Emancipation of Man, 1670-1752 (2006). Un ouvrage collectif reprenant les termes de ce débat a été publié en 2007 aux éditions Amsterdam sous le titre ; Qu'est-ce que les Lumières "radicales"? Libertinage, athéisme et spinozisme dans le tournant philosophique de l'âge classique. Le numéro 13 de Lumières poursuit cette discussion en proposant tout d'abord une interview électronique de Margaret Jacob et de Jonathan Israel à la manière des « regards croisés » de notre revue, puis cinq contributions de Fabienne Brugère, Yves Citton, Nicolas Dubos, Maiwenn Roudaut et Céline Spector.

2 Le concept de "Lumières radicales" au sens que lui donne Jonathan Israel est loin d'être admis comme opératoire par tous les chercheurs. Si tous les dix-huitièmistes acceptent l'existence de courants plus ou moins « radicaux» dans les Lumières, la définition, le sens et l'histoire de cette " radicalité » suscitent plus de divergences que d'accords avec la thèse initiale de Jonathan Israel. Il est inutile ici d'en reprendre les 
éléments principaux. On les trouvera résumés dans mon compte rendu de l'édition française de Radical Enlightenment dans le numéro 345 des AHRF (juillet-septembre 2006).

Depuis 2001, la thèse de Jonathan Israel a été l'objet de vives critiques de la part des historiens et des philosophes. Dans un numéro récent (2009/1) des Annales. Histoire, Sciences Sociales, Antoine Lilti en a proposé une lecture critique à la fois très convaincante, très exhaustive et très argumentée («Comment écrit-on l'histoire intellectuelle des Lumières ? Spinozisme, radicalisme et philosophie », Annales. Histoire, Sciences Sociales, 2009/1, 64 année, p. 171-206). J'y renvoie donc en me contentant ici d'indiquer les principaux points en débat.

On a remarqué d'abord que la démarche de recherche « d'influences » dans la lignée de l'histoire des idées utilisée par Israel ne permettait pas de contextualiser les débats, les passages, les réceptions, les transferts des textes et n'offrait finalement qu'une vision désincarnée des Lumières. Une autre critique touche au concept lui-même. La dichotomie entre "Lumières radicales » et « Lumières modérées » apparaitt comme une construction a posteriori et comme un lit de Procuste dans lequel Jonathan Israel cherche à faire rentrer des auteurs dont la pensée est plus complexe et plus évolutive. Enfin, le sens même de la radicalité telle que l'utilise Israel a été contesté. Pour lui, la radicalité est un monisme fondé sur le refus de la religion révélée, du déisme et de la transcendance du social et du politique. Or le lien entre le refus de la religion révélée et le radicalisme social et politique est loin d'être évident. L'athéisme ou le panthéisme sont-ils nécessairement égalitaires et démocratiques? La pensée athée peut très bien s'accommoder d'une conception aristocratique de la société qui considère que la crédulité des masses est un fait de nature. Enfin a contrario, l'égalitarisme et le républicanisme de Rousseau ne l'empêchent pas de développer une conception de la religion tout à fait opposée à celle du cercle holbachique, cela fait-il pour autant de Rousseau un "modéré " ? J'avais moi-même fait remarquer dans le compte rendu cité plus haut que l'un des points communs aux théoriciens regroupés par Israel sous le chapeau du "radicalisme » est qu'ils se trouvent presque tous en dehors du courant jusnaturaliste. Celui-ci implique en effet, une forme de transcendance du droit qui s'appuie à l'époque, soit sur une conception de la nature humaine comme émanation du divin, soit sur une conception morale de l'état de nature. Pour Israel, «l'amoralisme » philosophique est plus « radical » que l'école du droit naturel. Une des thèses les plus discutables d'Israel est d'ailleurs la caractérisation de la philosophie de Locke comme une réaction « modérée » au radicalisme spinozien. Israel considère que le droit naturel lockéen ne peut bénéficier de l'étiquette "radicale ", niant l'apport potentiellement révolutionnaire d'une pensée fondée sur l'idée d'une morale naturelle transcendante justifiant le droit à l'insurrection.

5 On retrouve l'ensemble de ces débats dans l'interview croisée entre Margaret Jacob et Jonathan Israel. La discussion porte d'abord sur la question de la chronologie des Lumières et de la pertinence du concept de « crise de conscience européenne » de Paul Hazard, puis sur la question du sens de la «radicalité ». Les deux auteurs débattent ensuite de la question des vecteurs du radicalisme et de sa traduction en termes politiques. Existe-t-il des Lumières « conservatrices », «nationales »? Quel est le statut de Locke dans le schéma de la radicalité selon Jonathan Israel ? Y a-t-il des apports de la franc-maçonnerie aux « Lumières radicales " ? Celles-ci défendent-elles une conception particulière du genre, de la race? 
6 Sans vouloir distribuer des satisfecit et des blâmes, j'avoue que la conception historique de Margaret Jacob me convainc nettement plus que l'approche d'Israel qui aboutit à des clivages largement artificiels. La catégorie des «Lumières conservatrices » englobant Locke, Montesquieu, Voltaire, Turgot et Kant est particulièrement confuse à mon sens. De même - mais ce n'est qu'un exemple parmi beaucoup d'autres - on ne voit pas très bien pourquoi Turgot se situerait dans les Lumières "conservatrices » et Condorcet dans l'héritage de la « radicalité »...

7 Les cinq contributions qui suivent cet échange sont consacrées au rapport de Hobbes aux «Lumières radicales» (Nicolas Dubos), à Montesquieu (Céline Spector), à la question du "genre» (Fabienne Brugère), de l'émancipation des Juifs (Maiwenn Roudaut), et enfin aux conséquences du paradigme des "Lumières radicales " sur le débat contemporain autour des Lumières (Yves Citton).

8 Dans l'ensemble, ces contributions sont plutôt critiques ou dubitatives quant au paradigme de Jonathan Israel. Le premier texte pose la question de la «modernité » et de la « radicalité » de Hobbes à la lumière des analyses de Leo Strauss et de Jonathan Israel. Le deuxième, celui de Céline Spector, revient sur la caractérisation de Montesquieu comme faisant partie des «Lumières conservatrices" (voire réactionnaires) par Israel au prisme de la question de l'émancipation des femmes. La démonstration est particulièrement convaincante: Montesquieu ne se laisse pas facilement enfermer dans des catégories a priori... Les contributions de Fabienne Brugère et Maiwenn Roudaut étudient l'utilité du concept de "Lumières radicales » appliqué aux questions du " genre » et de la tolérance dans les débats allemands sur les juifs. Enfin, le texte d'Yves Citton juge de sa pertinence dans les débats politiques du $\mathrm{xxI}^{\mathrm{e}}$ siècle sur l'actualité des Lumières. Il reconstruit le concept de «Lumières radicales" d'une manière très différente de celle de Jonathan Israel. La doxa contemporaine des critiques des Lumières comme "machine à nier la différence " (p. 155) peut être elle-même soumise à la radicalité des Lumières.

9 Pour conclure : si les «Lumières radicales » de Jonathan Israel peuvent apparaître aux historiens en particulier - comme un concept exagérément rigide et désincarné, le débat induit par ce questionnement est en revanche porteur de réflexions fructueuses. L'interview et les articles rassemblés ici en sont autant d'exemples. 